\title{
THE EFFECTS OF WHITE SOUND AND MUSIC UPON THE SUPERFICIAL PAIN THRESHOLD
}

\author{
J. G. Robson, M.B., Ch.B., F.F.A.R.C.S., ANd Harold T. Davenport, \\ M.B., F.F.A.R.C.S.*
}

THE CSE of white sound and music for the production of analgesia in dental surgery was developed by Gardner and Licklider ${ }^{1}$ and the method is now much used on the North American Continent. Gardner and Licklider reported that completely effective analgesia could be obtained in 63 per cent of patients who were having scaling or grinding operations or cavity preparation and Gardner, at the time of publication, stated that 136 extractions had been performed without recourse to other analgesia. Since this modest report many manufacturers have produced machines for the induction of "audio-analgesia" with not so modest claims for the effectiveness of the method, and we felt that it would be worth while to try to assess this objectively. Accordingly we selected the superficial pain threshold to a thermal stimulus and assessed the influence upon this of white sound and music. It was realized that the superficial pain elicited by heat is a different sensation to that elicited by an air turbine drill on a tooth, but we felt that it would allow the detection of any analgesic effect.

\section{Methods and Apparatus}

The instruments for the production of audio-analgesia|generally consist of a conventional tape-recorder playing pre-recorded tapes of music while white sound is produced and added by a conventional white sound generator. The music and white sound volumes are each under separate control by the patient. The patient is instructed to set the musie to a comfortable listening level and to concentrate upon this and not the operator. He is instructed to use the white sound in sufficient volume to abolish any pain that may be inflicted during operation. The analgesia conferred is thought to be a function of the white sound pressure, which can be adjusted to a point just below the pain threshold for hearing.

An audio-analgesia machine was obtained from one of the manufacturers, this being a production model as sold for use in dental surgeries. The music and white noise were supplied to the patient through an excellent pair of stereo-earphones, which efficiently damped out external noise. The tape recorder used two channels to supply stereophonic music and the reproduction was of high quality. The tape supplied had a varied repertoire of appropriate music. The white sound generator was limited to a maximum sound pressure level of $120 \mathrm{db}$., a pressure which should not damage hearing when used for relatively short periods but which approached the pain level for some of our subjects. By means of a foot switch the operator could lower the sound level in the earphones and communicate with the subject by an external microphone.

\footnotetext{
*Wellcome Research Department of Anaesthesia, McGill University, Montreal, and The Children's Memorial Hospital, Montreal, Quebec.
} 
Thirteen subjects, hospital residents, technicians, and nurses, were taken at random and the procedure was explained to each one in a non-committal manner and the machine and its function made clear. The superficial pain threshold was measured by means of a heated platinum wire, the temperature of which could be increased up to the point where the sensation of heat changed to one of pain. Three inches $(7.5 \mathrm{~cm}$.) of 0.01 -inch-diameter platinum wire was wound round a U-shaped glass rod $2.5 \mathrm{~mm}$. in diameter in such a way that when the convex part of the $U$ was placed on the skin only one-half of one turn made contact with the skin. The wire was connected to a stepdown mains transformer giving 6.3 volts from the secondary winding for 110 volts to the primary. The mains voltage was controlled by means of a "Variac" variable transformer. The subject was instructed to press the rod on to the thenar eminence of either hand with sufficient pressure so that the capillary blood flow under it was occluded. The primary voltage was increased at a slow and steady ratuntil the subject felt pain; then he removed the rod. The voltage at this point was recorded as the threshold. The method gives an empirical estimation of threshold in terms of voltage supplied to the wire. The procedure can lead to small burns on the skin, particularly when good analgesia is present, but the burns are superficial and heal quickly without visible scars. The risk was accepted by our subjects.

The subject was placed comfortably, supine on a theatre trolley. The earphones were applied and ten estimations of the threshold were made in each of the following conditions: (1) control with no sound or music; (2) music alone at a comfortable listening level, generally at one-tenth to three-tenths of the available maximum; (3) comfortable music with white sound at one-tenth of its maximum volume; (4) comfortable music with sound at three-tenths of its maximum volume; (5) comfortable music with maximum volume of white sound; (6) music at its maximum and white sound at its maximum; (7) repeat of control.

The sixth condition presented an overpowering volume of combined sound to the subject. Within the series the sequence 1 to 7 was varied at random.

Five of the subjects were given nitrous oxide at a later date and thresholds were again estimated. The concentration was either 20 per cent or 30 per cent of nitrous oxide in oxygen, control observations being made with oxygen alone. That this method of threshold estimation will detect the analgesia due to such weak concentrations of the gas has been demonstrated by Burns, Robson, and Welt. $^{2}$

\section{RESULTS}

The results are presented in Tables I and I]. Music alone or with white sound in any of the combinations tested had no significant influence on the threshold for superficial pain. The significance was tested for individual and grouped observations. Nitrous oxide, in concentrations of 20 per cent to 30 per cent in oxygen significantly raised the threshold for all individuals.

\section{Discussion}

It would appear that analgesia results from the administration of music and white sound in dental practice. ${ }^{1}$ In the short series of experiments conducted 
TABLE I

Superficial Pain Threshold Recorded as Volts Applied to a Heating IVire

Ilean values \pm the standard error of the observations. All means are of ten observations of threshold. The probability that the variations recorded between the control means and those of any of the treatments was due to chance is 0.3 to 0.6 . No combination of sound and music or of music alone influenced the superficial pain threshold in a significant manner

\begin{tabular}{|c|c|c|c|c|c|c|}
\hline $\begin{array}{l}\text { Subject } \\
\text { No. }\end{array}$ & $\begin{array}{c}\text { Control } \\
\text { conditions } \\
1,7\end{array}$ & $\begin{array}{c}\text { Music } \\
\text { comfortable, } \\
\text { condition } 2\end{array}$ & $\begin{array}{c}\text { Music } \\
\text { comfortable, } \\
\text { sound No. } 1 \text {, } \\
\text { condition } 3\end{array}$ & $\begin{array}{c}\text { Music } \\
\text { comfortable, } \\
\text { sound No. } 3 \text {, } \\
\text { condition } 4\end{array}$ & $\begin{array}{c}\text { Music } \\
\text { comfortable, } \\
\text { sound No. } 10, \\
\text { condition } 5\end{array}$ & $\begin{array}{c}\text { Music } \\
\text { very loud, } \\
\text { sound No. } 10, \\
\text { condition } 6\end{array}$ \\
\hline 1 & $71.10 \pm 0.852$ & $78.2 \pm 1.05$ & $76.4 \pm 1.67$ & $71.6 \pm 1.45$ & $70.0 \pm 1.70$ & $756 \pm 1.63$ \\
\hline 0 & & 73 & $1 \pm 1.06$ & $76.4 \pm 1.09$ & $77.9 \pm 157$ & $71.75 \pm 0$ \\
\hline 3 & $65.05 \pm$ & $66.60 \pm 0.89$ & $66.4 \pm 1.09$ & $65.2 \pm 1.03$ & $64.9 \pm 1.60$ & $67.8 \pm 0.84$ \\
\hline 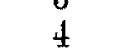 & $68.15 \pm$ & $64.80 \pm 0.83$ & $61.5 \pm 1.19$ & $62.2 \pm 0.96$ & $65.6 \pm 1.06$ & $67.9 \pm 0.73$ \\
\hline 5 & 59 & $60.5 \pm$ & $60.7 \pm 0.77$ & $59.5 \pm 1.38$ & $58.7 \pm 1.35$ & $61.3 \pm 0.74$ \\
\hline 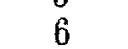 & $62.7 \pm$ & $59.9 \pm 0$ & \pm 0.70 & $63.35 \pm 0.41$ & $65.7 \pm 1.09$ & $66.15 \pm 1.32$ \\
\hline 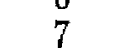 & \pm & $61.3 \pm 0.70$ & $59.3 \pm 0.72$ & $56.9 \pm 1.09$ & $58.5 \pm 1.44$ & $61.0 \pm 1.28$ \\
\hline 0 & \pm 0 & $55.0 \pm 1.08$ & \pm 0.75 & $53.2 \pm 0.73$ & $54.0 \pm 0.67$ & $51.1 \pm 0.56$ \\
\hline & \pm 0 & $63.9 \pm 0.74$ & $65.7 \pm 0.80$ & $65.3 \pm 1.25$ & $66.5 \pm 0 \quad 48$ & $65.3 \pm 0.73$ \\
\hline 10 & \pm 0 & $61.3 \pm 0.88$ & $61.7 \pm 0.65$ & $61.8 \pm 1.01$ & $61.8 \pm 0.81$ & $62.6 \pm 0.63$ \\
\hline 11 & \pm 0 & $57.8 \pm 1.37$ & $57.4 \pm 0.78$ & $58.2 \pm 0.96$ & $62.1 \pm 1.10$ & $62.1 \pm 1.11$ \\
\hline 1 & \pm & $61.7 \pm 2.27$ & $75.7 \pm 2.3 \pm$ & $71.9 \pm 2.50$ & $65.0 \pm 2.02$ & $80.8 \pm 2.71$ \\
\hline 13 & $63.2 \pm 0$ & $64.0 \pm 0.74$ & $65.1 \pm 0.74$ & $63.1 \pm 0.86$ & $64.5 \pm 0 \quad 65$ & $6+9 \pm 0.96$ \\
\hline
\end{tabular}

\section{TABLE II}

Superficial Pain Threshold Recorded as Volts Applied to a Heating Wire

The table gives the mean values \pm their standard errors with the number of observations in brackets. $P$ refers to the probability that the differences between the control and nitrous oxide means could have arisen by chance alone. All the differences between the control and nitrous oxide observations are statistically significant

\begin{tabular}{crlccc}
\hline \hline Subject & Control & & $\begin{array}{c}\text { Nitrous oxide, } \\
20 \% \text { to } 30 \%\end{array}$ & $\begin{array}{c}\text { Probability } \\
P\end{array}$ \\
\hline A & $63.6 \pm 0.62$ & $(20)$ & $73.9 \pm 1.29(10)$ & $<0.001$ \\
B & $63.5 \pm 1.17$ & $(20)$ & $80.0 \pm 1.91(10)$ & $<0.01$ \\
C & $61.2 \pm 1.04$ & $(20)$ & $66.1 \pm 093(10)$ & $<0.01$ \\
D & $75.8 \pm 2.38$ & $(20)$ & $94.2 \pm 2.15(10)$ & $<0.01$ \\
E & $78.0 \pm 268$ & $(20)$ & $91.5 \pm 1.90(10)$ & $<0.01$ \\
\hline
\end{tabular}

here no significant increase in the superficial pain threshold could be detected despite the wide range of sound and music pressures employed. Some attempt to explain the difference must be sought. The pain inflicted by an air turbine drill in the hands of a skilful dentist is relatively little and of brief duration. Considerable analgesia may result from the cooling spray and little additional analgesia may be required to provide comfort. If we presume that the audioanalgesia machine drowns the sound of the rotor and so produces a more relaxed patient then this pain may be made tolerable. Alternatively the sound may produce a hypnotic state, especially when strong suggestion is made by the practitioner. In our experiments no suggestion was made so that we might obtain a fairly objective estimate of analgesia. The method of testing itself ensured that the subject gave the onset of pain his full attention. Personal experience suggests that pleasant music alone can to some extent distract one from one's environment. 
With the white sound at its maximum/volume, logical thought $/$ seems to be impossible and one might think that pain would be ignored in this circumstance. However, in several subjects the temperature of the wire was raised to the point where pain was marked; no setting of the machine could be found where this pain could be in any way altered.

We, therefore, conclude that any effect that white sound or music has on the pain of dental work must either be due to the relative insignificance of the pain or to hypnotic suggestion.

\section{SUMMARY}

The effect of music and white sound upon the superficial pain threshold to a thermal stimulus was examined in thirteen subjects. No statistically significant alteration in the threshold was observed.

It was possible to detect a rise in this threshold of statistical significance with the administration of 20 to 30 per cent of nitrous oxide in oxygen.

The reported analgesic effects of white sound and music are discussed.

\section{ACKNOWLEDGMENTS}

We are indebted to Dr. H. McHugh for advice, to Mrs. Warburton for statistical help, and to the staff of the Montreal Children's Hospital for their co-operation.

\section{RÉsuMÉ}

L'effet de la musique et d'un son égal et continu sur le seuil de la douleur superficielle, recherché par un stimulus thermique, a été étudié chez treize sujets. Nous n'avons décelé aucune modification du seuil statistiquement significative.

Nous avons réussi à dépister, avec l'administration de 20 à 30 pour cent de protoxyde d'azote et d'oxygène, une élévation de ce seuil qui pourrait avoir une signification statistique.

Nous avons discuté des effets analgésiques d'un son égal et continu et de la musique.

\section{REFERENCES}

1. Gardner, W. J., \& Licklider, J. C. Auditory Analgesia in Dental Operations. J. Am. Dent. Assoc. 59: 1144 (1959).

2. Burns, B. D.; Robson, J. G.; \& Welt, P. J.L. The Effect of Nitrous Oxide upon Sensory Thresholds. Canad. Anaesth. Soc. J. 7: 411 (1960). 